(C) Э.В. Ахметгареева, А.Р. Ахунов, А.В. Боголюбов, Э.А. Ижбулатова, Р.Ш. Фатхутдинова DOI: http://doi.org/10.15350/2409-7616.2021.2.18

УДК 372.891

\author{
ФОРМИРОВАНИЕ ПРОФОРИЕНТАЦИОННЫХ ЗНАНИЙ НА УРОКАХ \\ ГЕОГРАФИИ (НА ПРИМЕРЕ ИЗУЧЕНИЯ КУРСА «ГЕОГРАФИЯ РОССИИ») \\ Э.В. Ахметгареева, А.Р. Ахунов, А.В. Боголюбов, Э.А. Ижбулатова, Р.Ш. \\ Фатхутдинова
}

\begin{abstract}
Ахметгареева Эльвира Вадимовна, студент кафедры геодезии, картографии и географических информационных систем факультета наук о Земле и туризма, ФГБОУ ВО «Башкирский государственный университет», Уфа, Россия.

E-mail: akhmetgareeva.elvira@mail.ru
\end{abstract}

Ахунов Артур Равилевич, кандидат географических наук, доцент кафедры туризма, геоурбанистики и экономической географии факультета наук о Земле и туризма, ФГБОУ ВО «Башкирский государственный университет», Уфа, Россия.

E-mail: ahun_84@mail.ru

Боголюбов Алексей Вячеславович, аспирант кафедры туризма, геоурбанистики и экономической географии, ФГБОУ ВО «Башкирский государственный университет», Уфа, Россия.

E-mail: alexejbogolyubov@gmail.com

Ижбулатова Эльвира Альбертовна, кандидат педагогических наук, доцент кафедры дошкольного и начального образования, Институт развития образования Республики Башкортостан, Уфа, Россия. E-mail: ielv@mail.ru

Фатхутдинова Регина Шамилевна, старший преподаватель кафедры геологии, гидрометеорологии и геоэкологии, ФГБОУ ВО «Башкирский государственный университет», Уфа, Россия.

E-mail: regishka1503@yandex.ru

Аннотация. Усиление работы по профессиональной ориентации подрастающего поколения - это требования современного общества. Школа всегда «снабжала» учашихся знаниями основ наук, знакомила с главными проблемами, стоящими перед намей страной. В данной статье показаны профориентационные возможности школьного курса географии России. Знакомство с профессиями осуществляется: при работе с текстом учебника, во время 
проведения практических работ в классе и на предприятии. Программа курса географии позволяет дать учащимся 9 класса значительную информачию о некоторых профессиях, связанных непосредственно с учебным материалом. Это чаще всего такие профессии как: металлист, механизатор, полевод, животновод, электромонтёр по ремонту $u$ обслуживанию электрооборудования, инженер-конструктор. В статье дается подробная информачия об отраслях промышленности и знакомство с ними на уроках географии. Учитель должен распределить материал про отрасли промышиленности по разделам, чтобы охватить весь объем профессиональной подготовки, который может быть предложен в ходе изучения экономической географии. Делается вывод, что сегодня у учителей географии недостаточно научно-методических рекомендаций по знакомству с профессиями в разных отраслях промышленности нашей страны. Отмечается, что по всем основным направлениям профориентационных возможностей необходимо постоянно обновлять методику обучения в конкретных условиях, которая была бы основной для совершенствования учебного процесса по получению знаний по предмету, в данном случае география. Профориентационное обучение должно обеспечить не только развитие эрудииии, оно призвано обеспечить их социализацию - воспитание всех нужных обществу психических черт учащихся: усидчивости, внимательности грамотности или в целом, приучать их к труду.

Ключевые слова: профориентация, географические специальности, курсы экономической географии, география в школе.

\section{UDC 372.891}

\section{FORMATION OF CAREER-ORIENTED KNOWLEDGE IN GEOGRAPHY LESSONS (ON THE EXAMPLE OF STUDYING THE COURSE «GEOGRAPHY OF RUSSIA»)}

E.V. Akhmetgareeva, A.R. Akhunov, A.V. Bogolyubov, E.A. Izhbulatova, R.S. Fatkhutdinova

Elvira V. Akhmetgareeva, Student of the Department of Geodesy, Cartography and Geographical Information Systems, Faculty of Earth Sciences and Tourism, Bashkir State University, Ufa, Russian Federation. E-mail: akhmetgareeva.elvira@mail.ru

Artur R. Akhunov, $\mathrm{PhD}$ (candidate of sciences in geography), Associate Professor of the Department of Tourism, Geo-Urban

Studies and Economic Geography, Faculty of Geosciences and Tourism, Bashkir State University, Ufa, Russian Federation. E-mail: ahun_84@mail.ru

Alexey V. Bogolyubov, 
Graduate Student of the Department of Tourism, Geourbanistics and Economic Geography, Bashkir State University, Ufa, Russian Federation. E-mail: alexejbogolyubov@gmail.com

Elvira A. Izhbulatova,

$\mathrm{PhD}$ (candidate of pedagogical sciences), Associate Professor of the Department of Preschool and Primary Education of the State Autonomous Educational Institution of Additional Professional Education of the Institute for the Development of Education of the Republic of Bashkortostan, Ufa, Russian Federation. E-mail: ielv@mail.ru

Regina S. Fatkhutdinova, Senior Lecturer, Department of Geology, Hydrometeorology and Geoecology, Bashkir State University, Ufa, Russian Federation. E-mail: regishka1503@yandex.ru

\begin{abstract}
Strengthening work on vocational guidance of the younger generation is a requirement of modern society. The school has always "supplied" students with knowledge of the basics of science, introduced them to the main problems facing our country. This article shows the career guidance opportunities of the school course in geography of Russia. Acquaintance with professions is carried out: when working with the text of the textbook, during practical work in the classroom and at the enterprise. The geography course program allows you to give 9th grade students significant information about some professions related directly to the educational material. These are most often such professions as: metalworker, machine operator, field breeder, livestock breeder, electrician for repair and maintenance of electrical equipment, design engineer. The article provides detailed information about industries and an introduction to them in geography lessons. The teacher should categorize the industry material to cover the entire training that can be offered in the study of economic geography. It is concluded that today geography teachers do not have enough scientific and methodological recommendations for acquaintance with professions in different industries of our country. It is noted that in all the main areas of career guidance opportunities, it is necessary to constantly update the teaching methodology in specific conditions, which would be the main one for improving the educational process to gain knowledge on the subject, in this case, geography. Vocational guidance training should ensure not only the development of erudition, it is designed to ensure their socialization - the upbringing of all the mental traits of students necessary for society: perseverance, attentiveness of literacy, or in general, to teach them to work.
\end{abstract}

Keywords: vocational guidance, geographical specialties, courses in economic geography, geography at school.

В современном стремительно меняющемся мире молодому поколению особенно важно правильно выбрать профессию, «унести» со школы нужный багаж знаний. Радикальные перемены в жизни нашего общества, обусловленные 
социальными и экономическими факторами, затрагивают все стороны общественной жизни, предопределяют мировосприятие людей.

Профессиональное становление личности - процесс многоплановый. Преломляясь через призму индивидуальных особенностей каждого человека, он предполагает наличие объективного и субъективного содержания. Этот процесс охватывает не только учебновоспитательную деятельность образовательных учреждений, но и все основные социально-экономические сферы общества. Школьник, находясь под "перекрестным огнем" все более возрастающего потока политической, экономической, научнотехнической информации, сталкивается с динамизмом происходящих событий: ориентация экономики на новые отношения, появление до сих пор неизвестных профессий, подъем социального престижа одних профессий и падение других [3]. Все эти факторы обуславливают необходимость целенаправленного управления процессом профессионального самоопределения школьников, поскольку в формировании творческой, деятельной, профессионально целеустремленной личности молодого человека участвует вся система деятельности и поведения, в которую он вовлекается.

Важно помочь каждому ребенку - овладеть основами знаний разных профилей и профессий, чтобы он смог совершить осознанный выбор. В данной статье мы рассмотрели профориентационные возможности школьного курса географии. Наша задача была вооружить их элементарными знаниями, которыми они смогут воспользоваться для понимания основных направлений развития современного мира. Курс «География России. Население и хозяйство» в профессиональной ориентации учащихся имеет исключительно важное значение. Он показывает целостную картину современного хозяйства нашей Родины, его структуру, особенности развития, размещения и перспективы. Содержание курса «География России. Население и хозяйство» России позволяет дать девятиклассникам огромную информацию о рабочих профессиях, занятых в сфере материального производства: горняк, металлист, механизатор, полевод, животновод, электромонтёр по ремонту и обслуживанию электрооборудования, инженер-конструктор, инженер-технолог и др. [15].

Многие сведения о профессиях содержатся в учебнике. Поэтому учителю при подготовке к занятиям следует внимательно отобрать необходимый материал с таким расчетом, чтобы охватить все стороны профессионального просвещения, заложенного в данном курсе.

Но ограничивать знакомство с профессиями учащихся 9 класса одними материалами из учебника не следует, их необходимо дополнять сообщениями учителя, практическими работами, учебными экскурсиями на производство, внеклассной и внешкольной работой, активно привлекать интернет-ресурсы [1].

Знакомство с профессиями начинается с первых уроков курса, следует дать более четкое представление о сферах труда в хозяйстве Российской Федерации. Необходимо особое внимание школьников обратить на следующие вопросы:

1. Какое влияние оказывают научно-технический прогресс и внедрение новых форм организации производства на географию отраслей хозяйства нашей страны?

2. Как развивается современное хозяйство России и её отдельных регионов; какие экономические и экологические проблемы стоят на пути модернизации основных отраслей и производств?

3. Какими специальностями необходимо овладеть для работы на предприятиях промышленности и сельского хозяйства, транспорта, в индустрии туризма? 
Учителю следует иметь в виду, что у многих школьников нет четкого понимания, что такое профессия, специальность, квалификация. Поэтому необходимо обратить на это особое внимание и пояснить учащимся, что такое профессия, специальность, квалификация, какая разница между этими терминами [2]. Профессия характеризует принадлежность работника к определенной трудовой категории и виду деятельности и требует от него определенных знаний и трудовых навыков, приобретаемых в обучении или опытом. Например, рассматривая тему «Энергетика», учитель называет ведущие профессии в угольной промышленности- горняк, в нефтяной - бурильщик и т. д.

Специальность охватывает более узкий вид деятельности в рамках профессии [9]. Например, профессия горняк имеет такие специальности: машинист врубовой машины, машинист угольного комбайна и т. п.

Можно привести пример из знакомой учащимся сферы труда, например школы. Профессия учителя объединяет учителей разных специальностей: преподавателей русского языка и литературы, математики, истории, географии и т. д. Далее рассмотрим отдельные темы, где можно знакомить обучающихся с профессиями.

Топливная промышленность включает несколько отраслей. Рассматривая каждую из этих отраслей, учитель дает сведения о ведущих рабочих профессиях нефтяной, газовой и угольной промышленности [7].

В нефтедобывающей и газовой промышленности ведущими рабочими специальностями являются бурильщик и аппаратчик. Бурильщики бурят скважины, а аппаратчики откачивают нефть и газ из глубин земли на поверхность.

Изучение угольной промышленности позволяет познакомить учащихся с профессией горняка. Учитель рассказывает ребятам о подземном и открытом способе добычи угля. Учащиеся рассматривают рисунок учебника «Схема угольной шахты и близлежащей территории» [4], после чего им предлагают ответить на вопросы: какой из названных способов добычи угля наиболее дешевый? При помощи каких механизмов производится добыча угля в карьере? Как называется профессия человека, обслуживающего этот механизм? Как называется профессия людей, добывающих полезные ископаемые подземным способом?

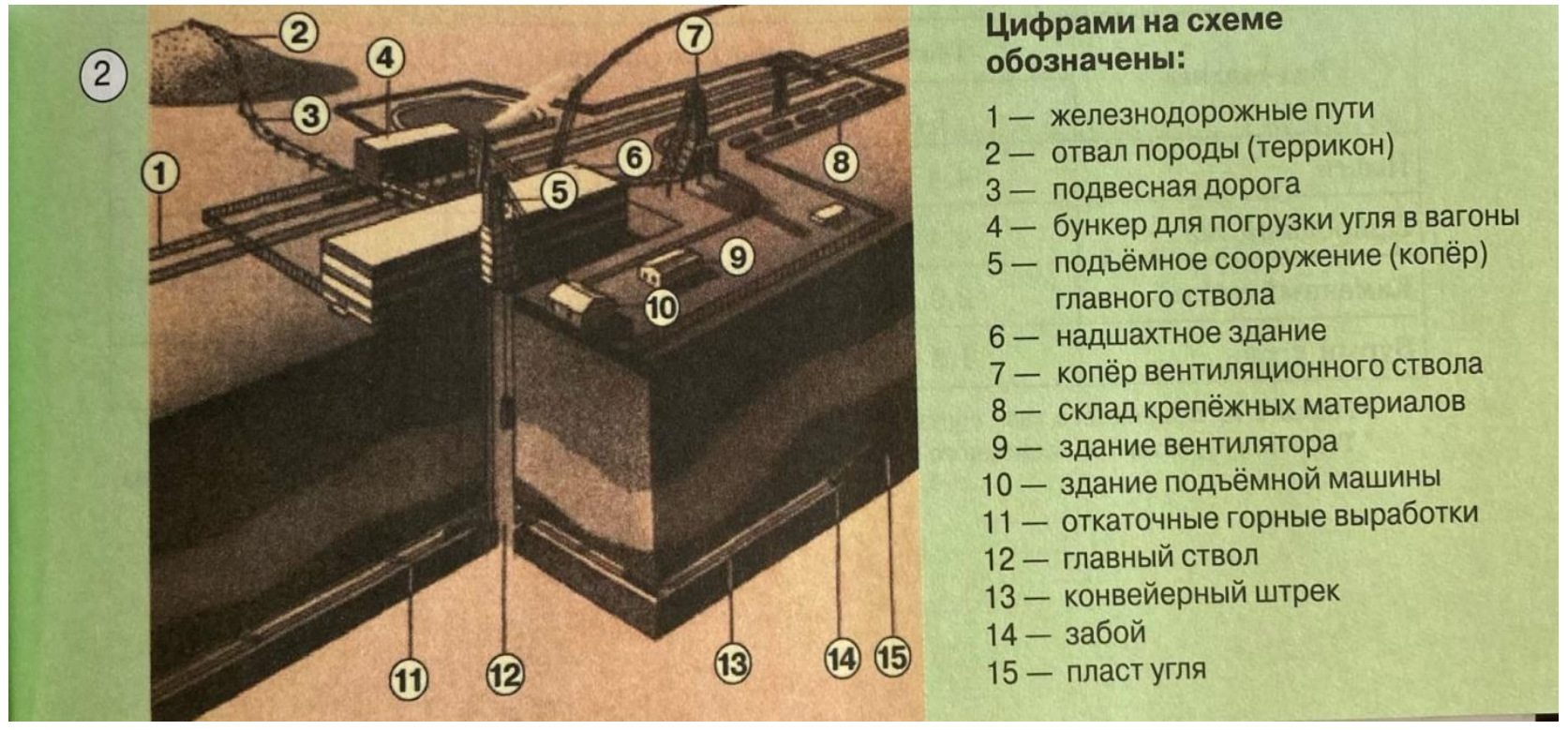


Рисунок 1 - Схема угольной шахты и близлежащей территории

Подкрепить ответы следует примерами. Шахтер - это профессия людей, занятых на подземной добыче полезных ископаемых. Проходчики, машинисты угольных комбайнов, горнорабочие очистного забоя — это люди отдельных специальностей, объединенные общей профессией — шахтер, или горняк. Труд современного шахтера облегчают самые разнообразные механизмы: угольный комбайн, врубовая машина, гидромониторная установка. С использованием современных механизмов резко возросла добыча каменного угля, сократилась доля участия ручного труда. Труд шахтера пользуется особым почетом в нашей стране. Шахтеры получают повышенную заработную плату, имеют сокращенный рабочий день, более продолжительный отпуск и право выхода на пенсию раньше, чем рабочие других профессий [10].

Материал темы «Металлургия» позволяет познакомить учащихся с большой группой специальностей, входящих в профессию, металлург. Учитель отмечает, что к профессиональной группе металлургов относятся работники, которые трудятся в производстве черных и цветных металлов. Металлурги - люди, занятые непосредственно в металлургическом процессе.

Представление учащихся о металлургах углубляется при знакомстве с типами предприятий и производственными процессами в черной и цветной металлургии. Учитель называет важнейшие специальности, входящие в профессиональную группу металлургов: горновые (доменный цех), сталевары (мартеновский цех), машинисты и операторы прокатных станов, вальцовщики (прокатные цехи) [6].

Подводя итоги урока, учитель заключает, что ведущая роль в металлургии принадлежит черной металлургии. Количество и качество выплавляемого металла определяют экономическую и оборонную мощь государства [5].

При изучении темы «Машиностроение РФ» можно предложить одному из учащихся выполнить на доске схему структуры машиностроительного завода с указанием ведущих профессий и специальностей.

Изучение нового материала в значительной мере должно опираться на личный опыт учащихся (юношей). Эти сведения школьников используются на уроке при объяснении подетальной и предметной специализации машиностроительных заводов.

Например, учащимся школ г. Уфы после посещения предприятия «УМПО» можно предложить ответить на следующие вопросы:

1. Какую продукцию выпускает предприятие?

2. Из каких узлов и деталей эта продукция состоит?

3. Какие детали делают?

4. Приведите примеры подетальной специализации (на примерах продукции известных вам машиностроительных заводов).

5. Почему наличие достаточного количества квалифицированных рабочих и научно-технических кадров - одно из условий, которое учитывается при размещении машиностроения?

Последующее изучение нового материала также в значительной мере опирается на личный опыт учащихся [12]. Естественно, что на этом уроке большую активность проявляют юноши, их опыт имеет доминирующее значение, а девушки являются слушателями.

При изучении темы «Лесная промышленность» необходимо показать 
учащимся хозяйственную роль этой отрасли промышленности, перспективы ее развития, достигнутые успехи. При этом важно показать школьникам технический уровень важнейших отраслей лесной промышленности, в первую очередь лесозаготовок.

Изучение темы можно начать с краткого сообщения о том, что лесная промышленность — одна из старейших в хозяйстве страны [11]. После рассказа учителя о составе и структуре лесной промышленности следует краткое сообщение одного из учеников об изменениях, которые произошли в лесной промышленности: «Совсем недавно в лесной промышленности были такие профессии, как возчик, сучкоруб, заготовители газочурок, работающие с помощью пилы лучковки, двуручной электропилы и бензопилы. В наше время все это уходит в прошлое [13]. На смену старому приходит новая техника, новая технология, а с ними приходят и новые профессии, требующие более высоких технических знаний: операторы, водители автопоездов, операторы полуавтоматических линий на нижних складах, диспетчеры по организации автотранспорта на вывозке леса».

При повторении и закреплении учебного материала на последующих уроках наряду с традиционными вопросами и заданиями необходимы следующие вопросы: какие механизмы используются на лесозаготовках? Чем интересна специальность лесоруба?

Урок на тему «Лесная промышленность» можно проводить и в несколько другом направлении. Изучение нового материала предусматривает знакомство с отраслью, ее составом и структурой, поэтому можно организовать экскурсию, например, на мебельную фабрику, или мебельные цеха в г. Уфа.

Рассказывая о специалистах, занятых на фабрике, необходимо говорить о высокой механизации производства, о том, что такой в прошлом трудоемкий процесс обработки древесины, как полировка, в настоящее время осуществляется за считанные минуты [14]. Вся подготовка деталей мебели проводится механизированным путем станочниками. И только сборку осуществляют вручную. Но на фабрике сохранились рабочие самой высокой квалификации - столяры краснодеревщики. Они создают образцы уникальной мебели, принимают участие в ремонте и реставрации старинной мебели.

Тема «Легкая промышленность» позволяет познакомить учащихся с рядом профессий этой отрасли. Легкая промышленность занимает ведущее место в производстве продукции, необходимой для развития народного хозяйства и повышения уровня жизни людей.

Текстильная промышленность Российской Федерации интенсивно оснащается новой техникой. Устаревшие ткацкие станки заменяются пневморапирными, бесчелночными и другими автоматическими станками (рисунок $2)$.

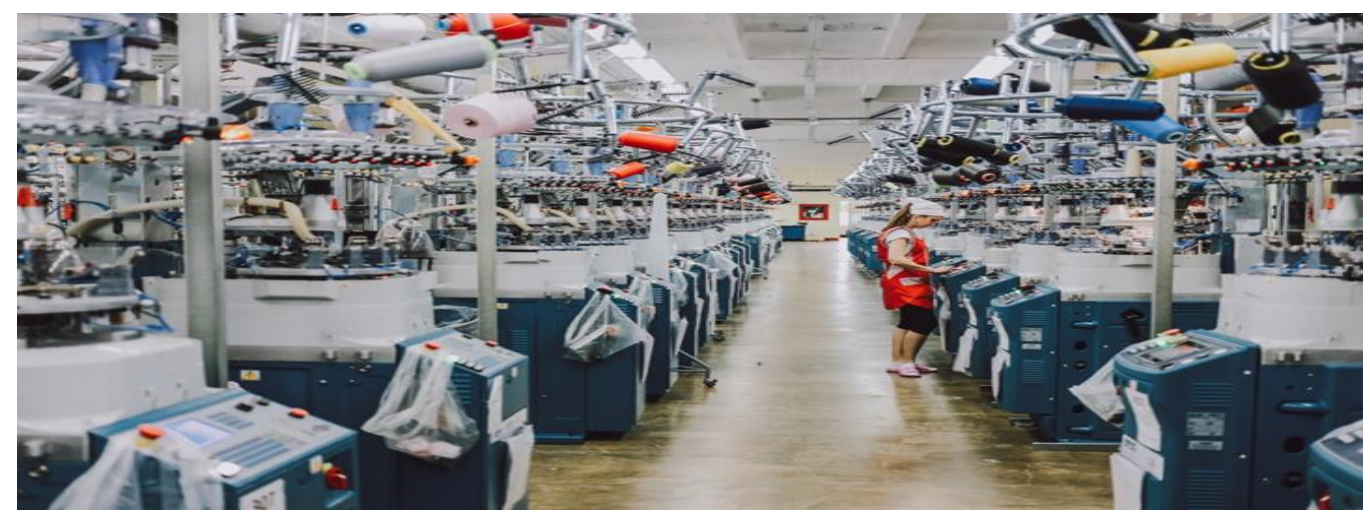


Рисунок 2 - Текстильная фабрика

С продукцией легкой промышленности учащиеся сталкиваются постоянно, но, несмотря на это, они не представляют многообразия ее отраслевого состава. Поэтому при изучении темы «Легкая промышленность» прежде всего, необходимо остановиться на ее составе и структуре.

Затем по таблице 1 «Отрасли текстильной промышленности» можно изучить её структуру и дополнить сведениями о центрах производства.

Таблица 1

Отрасли текстильной промышленности

\begin{tabular}{|c|c|c|c|c|c|}
\hline \multicolumn{6}{|c|}{ Отрасли текстильной промышленности } \\
\hline $\begin{array}{l}\text { Хлопчато- } \\
\text { бумажная }\end{array}$ & Шерстяная & Шелковая & Льняная & $\begin{array}{c}\text { Пенько- } \\
\text { джутовая }\end{array}$ & Трикотажная \\
\hline \multicolumn{6}{|c|}{ Центры } \\
\hline $\begin{array}{c}\text { Иваново } \\
\text { Шуя } \\
\text { Тверь }\end{array}$ & & & & & \\
\hline
\end{tabular}

В завершении можно предложить следующие вопросы:

1.Какие ведущие профессии в прядильном производстве?

2.Назовите ведущую профессию ткацкого производства.

3.Какие основные операции совершают во время работы ровенщица, прядильщица и ткачиха?

Изучение этой темы можно провести и совместно с учителем технологии несколько иначе. Она может кратко рассказать и продемонстрировать на образцах работу швеи легкого верхнего платья. Современное швейное производство высоко механизировано и базируется на научно обоснованных рекомендациях [8]. Здесь очень четко прослеживается разделение труда. Например, процесс изготовления пальто включает свыше 150 операций. Большинство из них механизировано (раскрой, утюжка, обметка, пришивание пуговиц, наметка петель и т. д.). Некоторые детали одежды можно продемонстрировать классу.

В любом крупном населенном пункте имеются предприятия пищевой промышленности. Поэтому знакомство учащихся с рабочими специальностями этой отрасли всегда может осуществляться на конкретных примерах. Например, посещение местного предприятия. Во время этой экскурсии девятиклассники знакомятся не только с технологическим процессом производства, со структурой предприятия, но и с рядом профессий.

В заключении отметим, что материалы данной статьи были апробированы на уроках географии в ЧОУ «Детская Академия» г. Уфа. Нами была проведена серия уроков, которая помогла понять, как расширить знания учащихся о мире профессий. Среди факторов, помогающих улучшить профориентационную работу в школе, назовем следующие:

1. Изменившиеся социально-экономические условия, вызвавшие появление новых профессий, часто незнакомых современному школьнику, требуют от учителя внимательного подхода к материалу уроков, где изучаются новые отрасли промышленности и хозяйства;

2. Усиление внимания к данной работе со стороны администрации школы и приведение ее в систему, учитывая особенности содержания разных предметов;

3. Расширение знаний выпускников педагогических вузов о путях и средствах организации профориентационной работы с учащимися. 
Важным фактором и, одновременно, условием правильности выбора профессии является формирование трудовых ценностных ориентаций школьников. Формирование трудовых ценностных ориентаций наиболее эффективно происходит при создании условий, где осуществляются личное знакомство школьников с различными профессиями.

\section{Литература:}

1. Алексеева М.Е. Возможности географии в профориентации обучающихся // Профессиональное самоопределение: современный аспект. - Киров: Межрегиональный центр инновационных технологий в образовании, 2020. - C. 26-29. URL: https://elibrary.ru/item.asp?id=42779669

2. Андрюшова Ю.С. Влияние современных тенденций в географической науке на процесс обучения географии в школе // Известия Пензенского государственного педагогического университета им. В.Г. Белинского. - 2006. - № 5. - C. 173-178. URL: https://elibrary.ru/item.asp?id=11728117

3. Ахметгареева Э.В., Нигматуллин А.Ф., Хизбуллина Р.З., Якимов М.С., Янчурин А.М. Знакомство с некоторыми географическими специальностями в процессе обучения географии в школе // ЦИТИСЭ. - 2020. - № 3. - С. 63-74. URL: https://elibrary.ru/item.asp?id=44064961

4. Быстрова Н.В., Казначеева С.Н., Мурыгин Н.С., Пасечник А.С. Профориентационная работа в школах как фактор повышения уровня самоопределения обучающихся // Инновационная экономика: перспективы развития и совершенствования. 2019. - № 3. - C. 42-47. URL: https://elibrary.ru/item.asp?id=38534641

5. Гайсин Р.И., Гилемханов И.Р., Хаялеева А.Д. Содержательно-методические аспекты формирования экономико-географической компетентности обучающихся школ на уроках географии // Современные наукоемкие технологии. - 2018. - № 5. - C. 235-239. URL: https://elibrary.ru/item.asp?id=35050143

6. Добржицкий Б.С. Знакомство с профессиями в обучении географии: (Из опыта работы). - М.: Просвещение, 1981. - 62 с.

7. Дойникова С.Е. Профориентационная направленность школьного курса географии // XXIX Ершовские чтения. Педагогическое образование: вызовы времени. Ишим: Ишимский педагогический институт им. П.П. Ершова, 2019. - С. 114-116. URL: https://elibrary.ru/item.asp?id=38308817

8. Машкина И.В., Никитина Ю.В., Осадчая Е.В. Роль чтения в формировании географических представлений школьников // Комплексные исследования детства. - 2019. T.1, № 3. - C. 232-245. URL: https://www.elibrary.ru/item.asp?id=42948261

9. Петракова С.В. Социально-экономическая география в школе//Актуальные проблемы науки и образования: прошлое, настоящее, будущее. - Тамбов: Консалтинговая компания Юком, 2012. - C. 93-93. URL: https://elibrary.ru/item.asp?id=22392886

10. Полкова А.С. Профориентационная работа в образовательной организации. Совершенствование профильного обучения и предпрофильной подготовки // Вестник Тогирро. - 2015. - № 2. - C. 61-62. URL: https://elibrary.ru/item.asp?id=25644381

11. Солодкова О.И. Особенности практического компонента в изучении курса экономической географии в средней школе // Моя профессиональная карьера. - 2021. - Т. 1, № 20. - C. 62-68. URL: https://elibrary.ru/item.asp?id=44692784

12. Шимлина (Рябцева) И.В. Анализ возможностей географического образования в профессиональном самоопределении учащихся современной школы // Наука и Школа. 2017. - №2. - C. 76-82. URL: https://www.elibrary.ru/item.asp?id=29072215

13. Dutta M. Place of life stories in labour geography: Why does it matter? // Geoforum. - 2016. - Vol.77. - P. 1-4. DOI: https://doi.org/10.1016/i.geoforum.2016.10.002 
14. Hinde E. Geography matters: Teacher beliefs about geography in today's schools // The journal of social studies research. - 2015 - Vol.39. - P. 55-62. DOI: https://doi.org/10.1016/j.jssr.2014.07.003

15. Piróg D. To study or not to study geography? The changing motivations behind choosing geography degree programmes by Polish students in the years 1995-2015 // Geoforum. 2018. - Vol.94. - P. 63-71. DOI: https://doi.org/10.1016/j.geoforum.2018.06.013

\section{References:}

1. Alekseeva M.E. Opportunities of geography in vocational guidance of students. Kirov, Interregional Center for Innovative Technologies in Education Publ., 2020, pp. 26-29. (In Russian) URL: https://elibrary.ru/item.asp?id=42779669

2. Andryushova Yu.S. The influence of modern trends in geographical science on the process of teaching geography at school. Izvestiya of the Penza State Pedagogical University named after V.I. V.G. Belinsky, 2006, no. 5, pp. 173-178. (In Russian) URL: https://elibrary.ru/item.asp?id=11728117

3. Akhmetgareeva E.V., Nigmatullin A.F., Khizbullina R.Z., Yakimov M.S., Yanchurin A.M. Acquaintance with some geographical specialties in the process of teaching geography at school. CITISE, 2020, no. 3, pp. 63-74. (In Russian) URL: https://elibrary.ru/item.asp?id=44064961

4. Bystrova N.V., Kaznacheeva S.N., Murygin N.S., Pasechnik A.S. Career guidance work in schools as a factor in increasing the level of self-determination of students. Innovative economy: prospects for development and improvement, 2019, no. 3, pp. 42-47. (In Russian) URL: https://elibrary.ru/item.asp?id=38534641

5. Gaisin R.I., Gilemkhanov I.R., Khayaleeva A.D. Substantive and methodological aspects of the formation of economic and geographical competence of students in geography lessons. Modern science-intensive technologies, 2018, no. 5, pp. 235-239. (In Russian) URL: https://elibrary.ru/item.asp?id=35050143

6. Dobrzhitsky B.S. Acquaintance with professions in teaching geography: (From work experience). Moscow, Prosveshchenie Publ., 1981. 62 p.

7. Doinikova S.E. Vocational orientation of the school course of geography. Ishim, Ishim Pedagogical Institute named after P.P. Ershova Publ., 2019, pp. 114-116. (In Russian) URL: https://elibrary.ru/item.asp?id=38308817

8. Mashkina I.V., Nikitina Yu.V., Osadchaya E.V. The role of reading in the formation of geographical representations of schoolchildren. Complex studies of childhood, 2019, vol.1, no.3, pp. 232-245. (In Russian) URL: https://www.elibrary.ru/item.asp?id=42948261

9. Petrakova S.V. Socio-economic geography at school. Tambov, Consulting company Ucom Publ., 2012, pp. 93-93. (In Russian) URL: https://elibrary.ru/item.asp?id=22392886

10. Polkova A.S. Career guidance work in an educational organization. Improvement of profile education and pre-profile training. Vestnik Togirro, 2015, no. 2, pp. 61-62. (In Russian) URL: https://elibrary.ru/item.asp?id=25644381

11. Solodkova O.I. Features of the practical component in the study of the course of economic geography in secondary school. My professional career, 2021, vol.1, no. 20, pp. 62-68. (In Russian) URL: https://elibrary.ru/item.asp?id=44692784

12. Shimlina (Ryabtseva) I.V. Analysis of the possibilities of geographic education in the professional self-determination of students of the modern school, Science and School, 2017, no. 2, pp.76-82. (In Russian) URL: https://www.elibrary.ru/item.asp?id=29072215

13. Dutta M. Place of life stories in labor geography: Why does it matter? Geoforum. 2016, vol.77, pp. 1-4. DOI: https://doi.org/10.1016/j.geoforum.2016.10.002 
14. Hinde E. Geography matters: Teacher beliefs about geography in today' s schools. The journal of social studies research. 2015, vol .39, pp. 55-62. DOI: https://doi.org/10.1016/j.jssr.2014.07.003

15. Piróg D. To study or not to study geography? The changing motivations behind choosing geography degree programs by Polish students in the years 1995-2015. Geoforum, 2018, V.94, pp. 63-71. DOI: https://doi.org/10.1016/j.geoforum.2018.06.013

Submitted: 10 April 2021 